\title{
Research on the First Breaking Mechanism of the Main Roof of Coal Seam with High Dip Angle
}

\author{
Xinyu $\mathrm{Hu} \mathbb{D}^{1,2}$ and Jinlong Cai $\mathbb{i D}^{3,4}$ \\ ${ }^{1}$ College of Mechanics and Civil Engineering, China University of Mining and Technology, Xuzhou, Jiangsu 221116, China \\ ${ }^{2}$ State Key Laboratory for Geomechanics and Deep Underground Engineering, China University of Mining \& Technology, \\ Xuzhou, Jiangsu 221008, China \\ ${ }^{3}$ School of Energy and Safety Engineering, Anhui University of Science and Technology, Huainan, Anhui 232001, China \\ ${ }^{4}$ School of Architecture and Civil Engineering, West Anhui University, Luan, Anhui 237012, China \\ Correspondence should be addressed to Jinlong Cai; 25072103@qq.com
}

Received 7 June 2020; Revised 28 August 2020; Accepted 6 September 2020; Published 16 September 2020

Academic Editor: Hailing Kong

Copyright (c) 2020 Xinyu Hu and Jinlong Cai. This is an open access article distributed under the Creative Commons Attribution License, which permits unrestricted use, distribution, and reproduction in any medium, provided the original work is properly cited.

In order to study the mechanism and characteristics of the first breaking of the roof in thick coal seams with high dip angles, a mechanical model of elastic thin plate with four clamped edges of the roof was established, and the expressions of the deflection and stress of the roof were obtained by the energy method. The influence of the change in seam dip angle on the first breaking distance of the roof was presented. Based on the stress solution, the roof breaking criterion was proposed, and the breaking distance of the roof was calculated. Combined with numerical simulation, the stress distribution characteristics of the upper and lower surfaces of the stope roof were analyzed. The results show that the first breaking distance of the roof is inversely proportional to the seam dip angle. Broken morphology of roof in high dip seam is different from the "O-X" morphology of horizontal roof. The roof breaking order of the seam with high dip angle is middle-middle upper-middle lower-upper-lower. These research results have certain theoretical guiding significance for the study of the first breaking mechanism of the main roof of highly inclined working face of coal seams.

\section{Introduction}

The activity of surrounding rock is closely related to mine pressure. The former is the internal source of the latter, and the latter is the external manifestation of the former. Hence, the study of roof movement in stope is the basis of mine pressure analysis [1]. As the key rock layer that affects the mine pressure, scholars at home and abroad have conducted a significant amount of in-depth research on the breaking mechanism of the main roof in near horizontal or gently inclined coal seams. Many theories of mine pressure control have been proposed, such as pressure arch hypothesis, cantilever hypothesis, masonry beam hypothesis, and moving rock beam hypothesis [2].

However, the breaking law of the inclined coal seam roof is different from that of the near horizontal coal seam. The roof behaviors show obvious asymmetry, which cannot be described accurately by the above traditional hypotheses.

Yin et al [3] analyzed the basic laws of rock mass movement, mine pressure distribution, and ground subsidence caused by mining in large inclined working face by establishing FLAC numerical model. Based on the thin plate theory, Zhang et al. [4] analyzed the roof breaking of up-dip or down-dip mining stope. According to the theory of elastic mechanics, Wang et al. [5] established a mechanical model of the roof in the thick seam with large dip angle and analyzed its fracture characteristics. Using R-W Kane theory and Lagrange theory, Wu et al. [6-8] established the general dynamic equation of the coal seam with high dip angle and conducted in-depth research on the mechanism of the main roof fracture with high dip angle. In this paper, based on the engineering background of a mining face with high dip angle 
in Luliang mining area, an elastic thin plate model with four clamped edges was established. The expressions of deflection and stress were obtained by energy method, and the influence of different inclinations on the roof deflection was analyzed. Combined with numerical calculation, the roof breaking law was analyzed and verified by on-site data.

\section{General Situation of Engineering Geology}

The average buried depth of working face 103 in Luliang mining area is $485 \mathrm{~m}$. The main mining coal seam is No. 5 coal seam. The inclined length of working face is $185 \mathrm{~m}$, the strike length is $1700 \mathrm{~m}$, and the average thickness of coal seam is $4.7 \mathrm{~m}$. The dip angle of coal seam is $26^{\circ}-32^{\circ}$, with an average of $30^{\circ}$. The lithology of roof and floor is shown in Table 1.

2.1. Mechanical Analysis of Thin Plate Model. According to the theory of mine pressure in stope, the first fracture of main roof can be explained more reasonably by the elastic thin plate model with four edges clamped [9-11]. Generally, the working face is $150 \mathrm{~m} 200 \mathrm{~m}$ long, the first breaking distance of the basic roof is $20 \mathrm{~m} \sim 50 \mathrm{~m}$, and its width thickness ratio is $1 / 5 \sim 1 / 10$. Hence, the main roof can be regarded as a thin plate.

2.2. Establishment of Mechanical Model. Figure 1 shows the mechanics model of the main roof before first breaking, which is an elastic thin plate with four edges clamped. For this working face, $a$ is the advancing distance, $b$ is the inclination length, and $\alpha$ is the inclination angle. For the rock in main roof, $E$ is the elastic model, and Poisson's ratio is $\mu$. The term $h$ is the thickness of main roof, that is, the thickness of thin plate in elasticity. For simplification, the load $q(x)$ acting on the roof is regarded as the resultant force of the longitudinal load and the inclined load. Then, the Ritzi energy method is used for calculation [12].

2.3. Deflection and Stress Equation of Main Roof. In order to meet the asymmetrical distribution of the main roof deflection along the inclination, the following deflection functions $\omega(x, y)$ can be used:

$$
w=\sum_{m=1}^{\infty} \sum_{m=1}^{\infty} c_{m n}\left(1-\cos \frac{2 \pi m x}{a}\right)\left(1-\cos \frac{2 \pi n y}{b}\right) .
$$

The boundary conditions are

$$
\begin{array}{r}
\left.w\right|_{x=0}=\left.w\right|_{x=a}=\left.w\right|_{y=0}=\left.w\right|_{y=b}=0, \\
\left.\frac{\partial w}{\partial x}\right|_{x=0}=\left.\frac{\partial w}{\partial x}\right|_{x=a}=\left.\frac{\partial w}{\partial y}\right|_{y=0}=\left.\frac{\partial w}{\partial y}\right|_{y=b}=0 .
\end{array}
$$

Based on the assumption of straight line of the thin plate bending and by neglecting the middle-plane strain, its total deformation energy is obtained as follows:

$$
U=\frac{\pi^{2} E h^{3}}{6\left(1-\mu^{2}\right)} \sum_{m=1}^{\infty} \sum_{n=1}^{\infty} c_{m n}^{2}\left(\frac{3 b m^{4}}{a^{3}}+\frac{3 a n^{4}}{b^{3}}+\frac{2 m^{2} n^{2}}{a^{2} b^{2}}\right)
$$

The work done by the load on the plate surface is

$$
W=\iint_{S} q \cos \alpha w \mathrm{~d} x \mathrm{~d} y+\frac{1}{2} \iint_{s} q \sin \alpha y\left(\frac{\partial w}{\partial y}\right)^{2} \mathrm{~d} x \mathrm{~d} y .
$$

The total potential energy of the plate is $\Pi=U-W$. From the principle of minimum potential energy, i.e., $\partial \prod / \partial c_{m n}=0$, each coefficient $c_{m n}$ can be obtained. Then, the deflection expression is

$$
w=\sum_{m=1}^{\infty} \sum_{n=1}^{\infty} \frac{q \cos \alpha}{\left(4 \pi^{2} E h^{3} / 12\left(1-\mu^{2}\right)\right)\left(\left(3 m^{4} / a^{4}\right)+\left(3 n^{4} / b^{4}\right)+\left(2 m^{2} n^{2} / a^{3} b^{3}\right)\right)-\left(q \sin \alpha \pi^{2} n^{2} / b^{2}\right)}(1-\cos (2 \pi m x / a))(1-\cos (2 \pi n y / b)) .
$$

Substituting equation (5) into the formula giving the relationship between the deflection and the stress of the rectangular thin plate in elastic mechanics, three stress components of the main roof of the high dip seam are obtained as follows:

$$
\begin{gathered}
\sigma_{x}=-\frac{4 \pi^{2} E z q \cos \alpha}{\left(1-\mu^{2}\right)} \sum_{m=1}^{\infty} \sum_{n=1}^{\infty} \frac{\left(\left(m^{2} / a^{2}\right) \cos (2 \pi m x / a)(1-\cos 2 \pi n y / b)+\mu\left(n^{2} / b^{2}\right) \cos (2 \pi n y / b)(1-\cos 2 \pi m x / a)\right)}{4 \pi^{2} E h^{3} / 12\left(1-\mu^{2}\right)\left(\left(3 m^{4} / a^{4}\right)+\left(3 n^{4} / b^{4}\right)+\left(2 m^{2} n^{2} / a^{3} b^{3}\right)\right)-\left(q \sin \alpha \pi^{2} n^{2} / b^{2}\right)} \\
\sigma_{y}=-\frac{4 \pi^{2} q \cos \alpha E z}{\left(1-\mu^{2}\right)} \sum_{m=1}^{\infty} \sum_{n=1}^{\infty} \frac{\left(\left(n^{2} / b^{2}\right) \cos (2 \pi n y / b)(1-\cos (2 \pi m x / a))+\mu\left(m^{2} / a^{2}\right) \cos (2 \pi m x / a)(1-\cos 2 \pi n y / b)\right)}{\left(4 \pi^{2} E h^{3} / 12\left(1-\mu^{2}\right)\right)\left(\left(3 m^{4} / a^{4}\right)+\left(3 n^{4} / b^{4}\right)+\left(2 m^{2} n^{2} / a^{3} b^{3}\right)\right)-\left(q \sin \alpha \pi^{2} n^{2} / b^{2}\right)} \\
\tau_{x y}=-\frac{4 \pi^{2} q \cos \alpha E z}{a b(1+\mu)} \sum_{m=1}^{\infty} \sum_{n=1}^{\infty} \frac{m n \sin (2 \pi m x / a) \sin (2 \pi n y / b)}{\left(4 \pi^{2} E h^{3} / 12\left(1-\mu^{2}\right)\right)\left(\left(3 m^{4} / a^{4}\right)+\left(3 n^{4} / b^{4}\right)+\left(2 m^{2} n^{2} / a^{3} b^{3}\right)\right)-\left(q \sin \alpha \pi^{2} n^{2} / b^{2}\right)} .
\end{gathered}
$$


TABLE 1: Features of coal seam roof and floor.

\begin{tabular}{|c|c|c|c|}
\hline Roof or floor & Rock type & Thickness (m) & Lithological characteristics \\
\hline Main roof & $\begin{array}{l}\text { White } \\
\text { sandstone }\end{array}$ & $3.6 \sim 6.5 / 4.7$ & $\begin{array}{r}\text { Light gray sandstone with medium grains, hard, with ver } \\
\text { joint, compressive strength } 84.8 \mathrm{MPa} \text {, incl }\end{array}$ \\
\hline $\begin{array}{l}\text { Immediate } \\
\text { roof }\end{array}$ & Gudstone & $10 \sim 21 / 15$ & $\begin{array}{l}\text { Black mudstone with bright strip, brittle, developed joint, compressive strength } \\
15.8 \mathrm{MPa} \text {, inclination } 29^{\circ}\end{array}$ \\
\hline $\begin{array}{l}\text { Immediate } \\
\text { floor }\end{array}$ & Iud & 10 & $\begin{array}{c}\text { Grayish black mudstone, dense and massive, mainly composed of argillaceous } \\
\text { components, containing a large amount of plant fossil, developed joint, compressive } \\
\text { strength } 18.5 \mathrm{MPa} \text {, inclination } 29^{\circ}\end{array}$ \\
\hline Main floor & Sandstone & $1 / 2.5$ & $\begin{array}{l}\text { Gray white sandstone, mainly composed of quartz, with carbon chips and carbon } \\
\text { stripes, undeveloped joint, compressive strength } 38 \mathrm{MPa} \text {, inclination } 29^{\circ}\end{array}$ \\
\hline
\end{tabular}
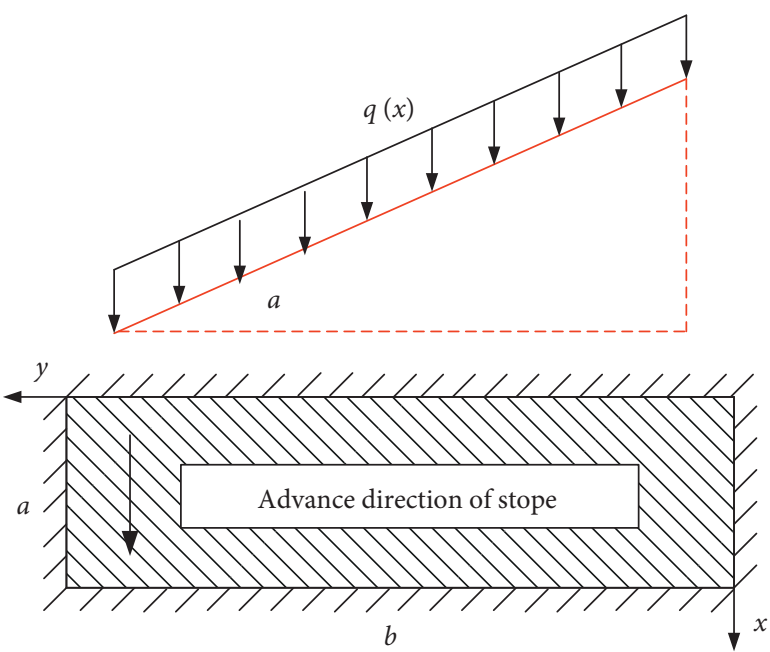

FIGURE 1: Thin plate model of main roof for mining high dip seam.

From the expressions of deflection and stress, it can be seen that the fracture shape of elastic rectangular thin plate is related to its geometric parameters.

\subsection{The Criterion of Roof Breaking in High Angle Stope.} The tensile strength of rock is less than its shear strength and compressive strength, and the stress release is obvious after the roof breaking. Once tensile failure has occurred at some part, other forms of failure are not considered. Therefore, the main failure mode of rectangular thin plate is tension failure.

As the inclined length of working face 103 is much longer than its other dimensions, the following criterion was set up. When the tensile stress in $Y$ direction reaches the ultimate tensile strength, the advancing distance of working face is considered as the breaking distance of rock plate. The final solution can be approximated in the form of iteration.

\section{Analysis of the First Breaking of the Main Roof in the Seam with High Dip Angle}

The trial calculation of equation (5) shows that the warped surface of rock plate tends to balance gradually till $m=20$, $n=20$. To obtain the influence of the dip angle of seam on the first breaking distance of the main roof, and the regularity of the first breaking along the inclination of the working face, the following parameters were set in accordance with the overlying rock parameters of working face 103 . The thickness of the main roof is $h=4.7 \mathrm{~m}$, the rock modulus of elasticity is $E=30 \mathrm{GPa}$, self-weight of overlying rock is $11.25 \mathrm{MPa}$, and the inclined length of working face is $b=185 \mathrm{~m}$.

3.1. Influence of Dip Angle on the First Breaking of Main Roof. The first breaking distance of the main roof was analyzed under six inclination angles of $15^{\circ}, 25^{\circ}, 35^{\circ}, 45^{\circ}, 55^{\circ}$ and $65^{\circ}$. Due to the limited space, only three cases of $25^{\circ}, 35^{\circ}$ and $45^{\circ}$ are listed, and their warped surfaces are shown in Figures $2-4$. In the figure, $x, y$, and $z$ represent the inclined length of the working face, the advancing distance of the working face, and the displacement of the roof, respectively.

It can be seen from Figures 2-4 that the reverse displacement of the warped surface occurs as the working face advances, which is obviously inconsistent with the actual low-order response. Hence, it can be inferred that the roof is broken during this propulsion section. Specifically, Figure 2(a) shows that when the advancing distance of the working face is $30 \mathrm{~m}$, the bending surface is normal, and the roof with an inclination of $15^{\circ}$ is intact, while Figure 2(b) shows that when the advancing distance is $40 \mathrm{~m}$, the bending surface is abnormal, and the roof is broken. This indicates that the roof is damaged at some time between $30-40 \mathrm{~m}$. Figures 3 and 4 similarly illustrate the advancing distance of working face when the roofs with dip angles of $35^{\circ}$ and $45^{\circ}$ are broken. Through further calculation, Figure 5 shows the breaking step distance of main roof at different inclination angles of seam.

It can be seen from Figure 5 that the initial breaking distance of roof decreases with the increase in seam dip angle. More specifically, when the seam dip angle is greater than $45^{\circ}$, the variation of the first breaking distance is slow. When the seam dip angle is less than $45^{\circ}$, it becomes faster.

3.2. Variation of the Breaking Distance along the Inclination of Working Face. To analyze the change in breaking distance along the inclination of working face, the selected parameters are $\alpha=25^{\circ}$ and tensile strength of main roof rock of $10 \mathrm{MPa}$, in accordance with the specific conditions of working face 103 and the above fracture criteria. The calculation results are shown in Figure 6.

It can be seen from Figure 6 that the breaking distance on both sides of the roof is large, and the breaking distance in 


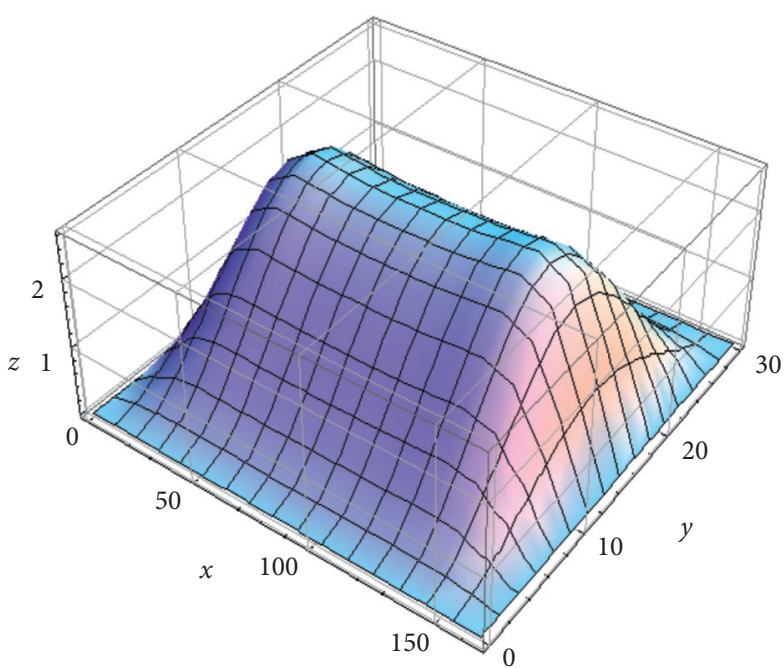

(a)

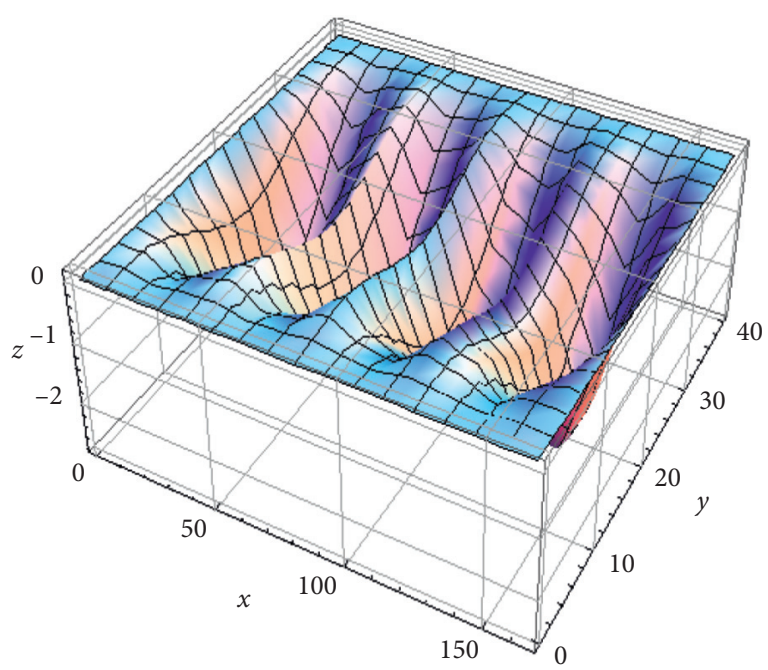

(b)

Figure 2: Roof deflection at an inclination angle of $25^{\circ}$. (a) Advancing distance of $30 \mathrm{~m}$. (b) Advancing distance of $40 \mathrm{~m}$.

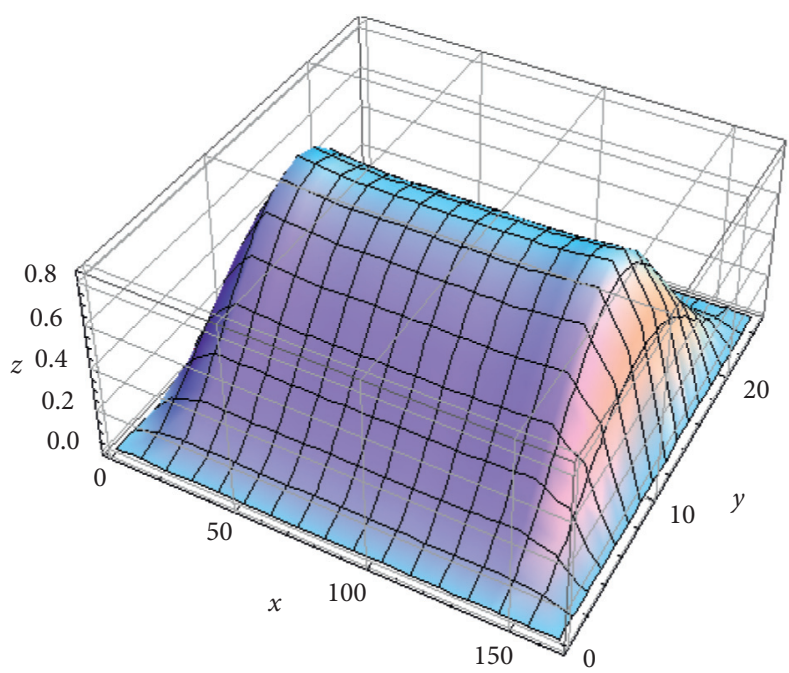

(a)

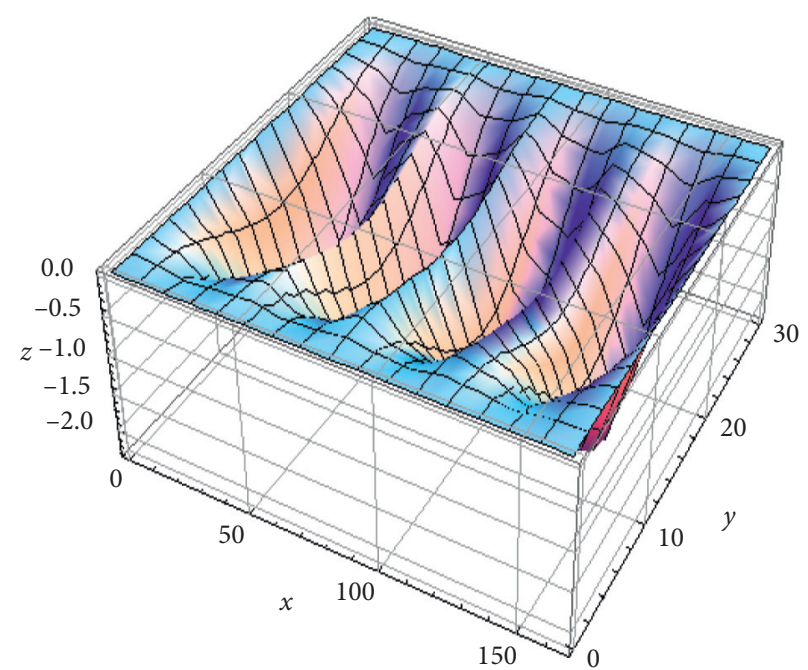

(b)

Figure 3: Roof deflection at an inclination angle of $35^{\circ}$. (a) Advancing distance of $25 \mathrm{~m}$. (b) Advancing distance of $30 \mathrm{~m}$.

the middle is the smallest, which forms a " $V$ " shaped breaking surface. The maximum value of the breaking distance difference is as high as $10 \mathrm{~m}$. On the whole, the first breaking distance of roof is about $30 \mathrm{~m}$, which is similar to the data analyzed with warped surface.

\section{Numerical Analysis of Thin Plate}

4.1. Establishment of Numerical Model. To analyze the roof stress and the mechanism of roof fracture, numerical calculation was performed using a literature method [4] and the D-P strength criterion, which is closer to rock properties. It was assumed that there is main roof strata in the high dip stope, with a length of $b=185 \mathrm{~m}$ (along the inclination of working face, i.e., the $y$ direction), a width of $a=30 \mathrm{~m}$ (the $x$ - direction), a thickness of $h=4.7 \mathrm{~m}$ and a dip angle of $\alpha=30^{\circ}$. Using ANSYS software, solid 185 three-dimensional solid element was selected to establish the model. According to the boundary conditions before the first fracture of the main roof, its four edges can be clamped for simulation. A linear load varying along the depth is applied to the upper surface of the model, as shown in Figure 7 . The angle between the load and the plate is $30^{\circ}$. Then, the load is divided into a component perpendicular to the plate and a component parallel to the plate.

4.2. Analysis of the First Breaking Mechanism of the Main Roof of the Steep Seam. Figures 8 and 9 show the stress distribution characteristics on the main roof surface during first breaking. 


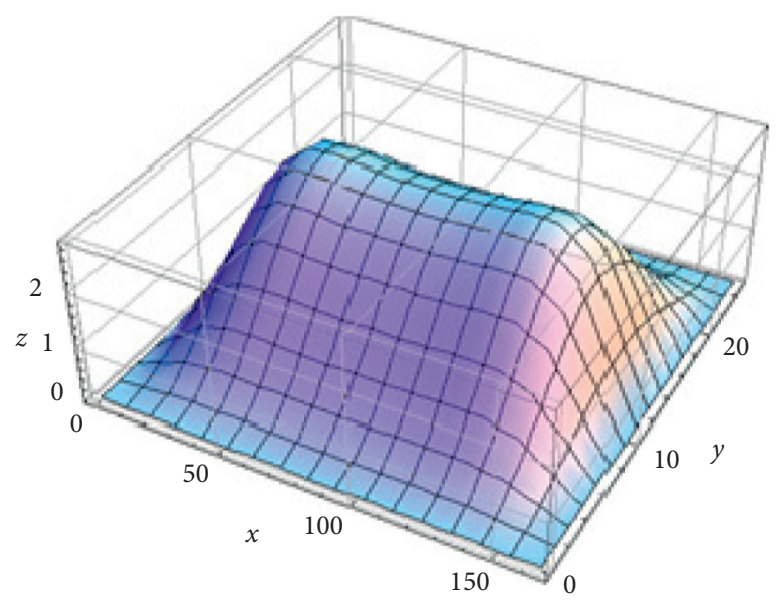

(a)

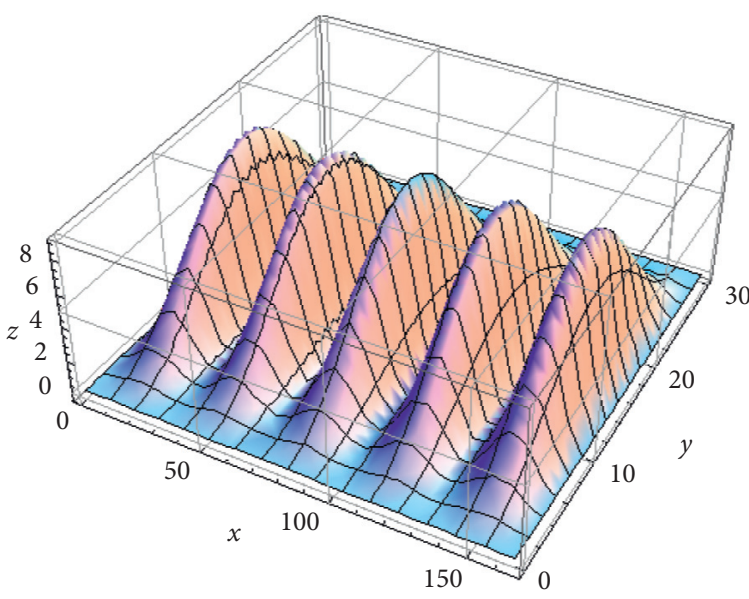

(b)

Figure 4: Roof deflection at an inclination angle of $45^{\circ}$. (a) Advancing distance of $25 \mathrm{~m}$. (b) Advancing distance of $30 \mathrm{~m}$.

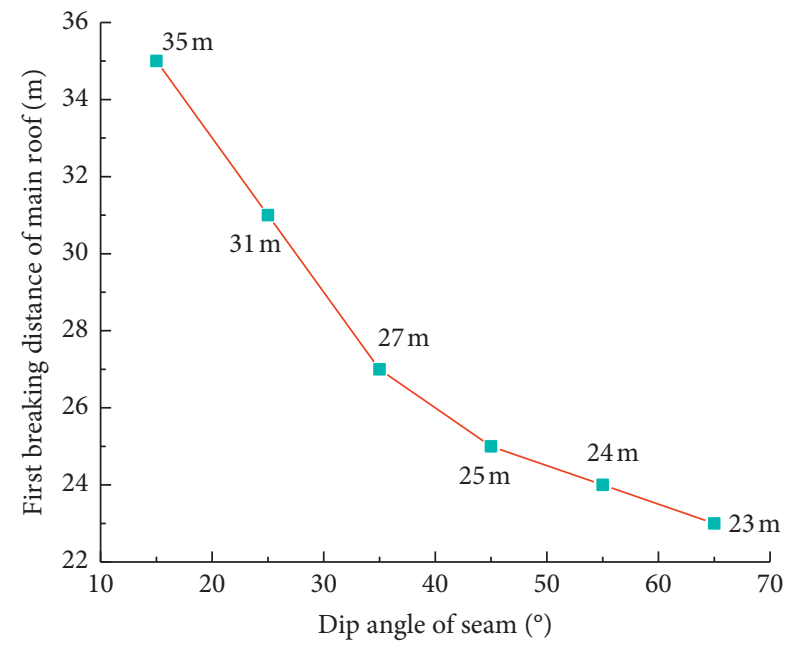

FIGURE 5: Variation of the first breaking distance of the roof with inclination angle.

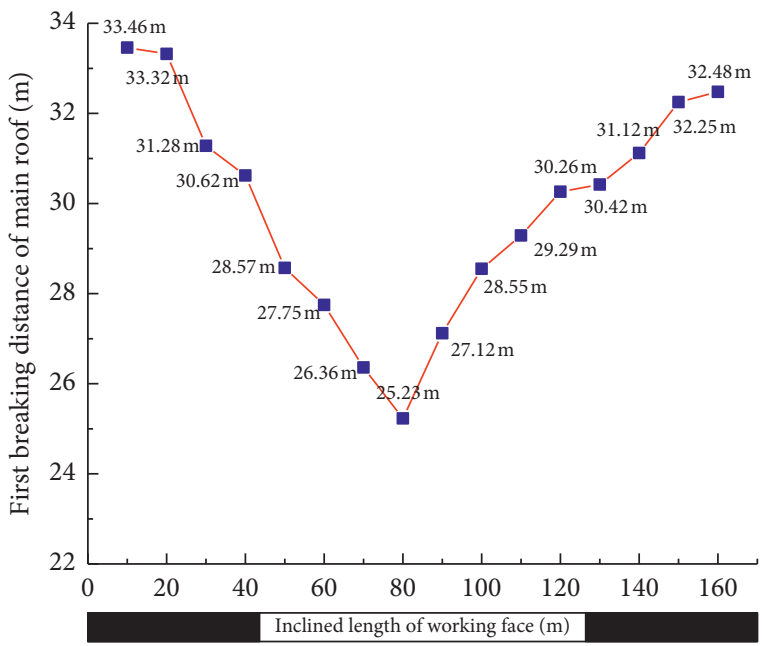

FIGURE 6: Change in the first breaking distance along the inclination of working surface.

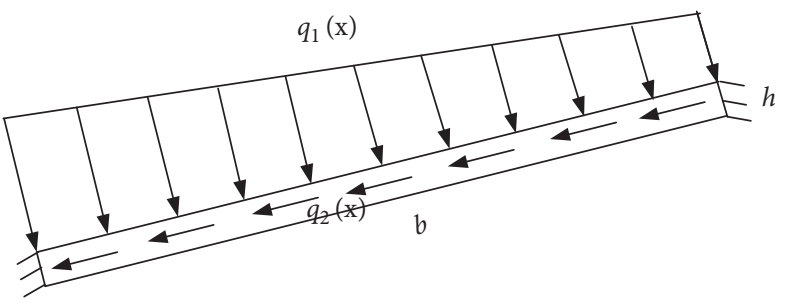

Figure 7: Sketch of model with applied load.

It can be seen from Figures 8 and 9 that the roof stress of the steep seam is asymmetric, which is different from that of the horizontal seam. Figure 8 shows the stress distribution in the $X$ direction. On the upper surface, the center of the two long sides forms the maximum tensile stress area, and the center is the O-type compressive stress area. On the lower surface, the center forms the O-type tensile stress area, and the center of the two long sides is the compressive stress area.

Figure 9 shows the stress distribution in the $Y$ direction. On the upper surface, the center of the short edge at the right end (upper part of the working face) forms the maximum tensile stress area, and the upper surface forms the "C" type tensile stress area and the triangular compressive stress area. On the lower surface, the left short edge receives the maximum compressive stress, and the lower surface forms the triangular tensile stress area. According to these distribution characteristics of the stress, it can be seen that the stress in $Y$ direction (along the inclination of working face) causes the breaking mechanism of the roof of the steep seam to be different from that of the horizontal seam.

As a brittle material, the tensile strength of rock is far less than its compressive strength. It can be seen from the stress distribution that, on the upper surface, the central area of the two long sides (the maximum tensile stress area) will be damaged first, forming cracks that extend to both sides, and then through the central maximum tensile stress area of the short side (the upper part of the working face) on the right side to form a "U" type crack. On the lower surface, the peak 


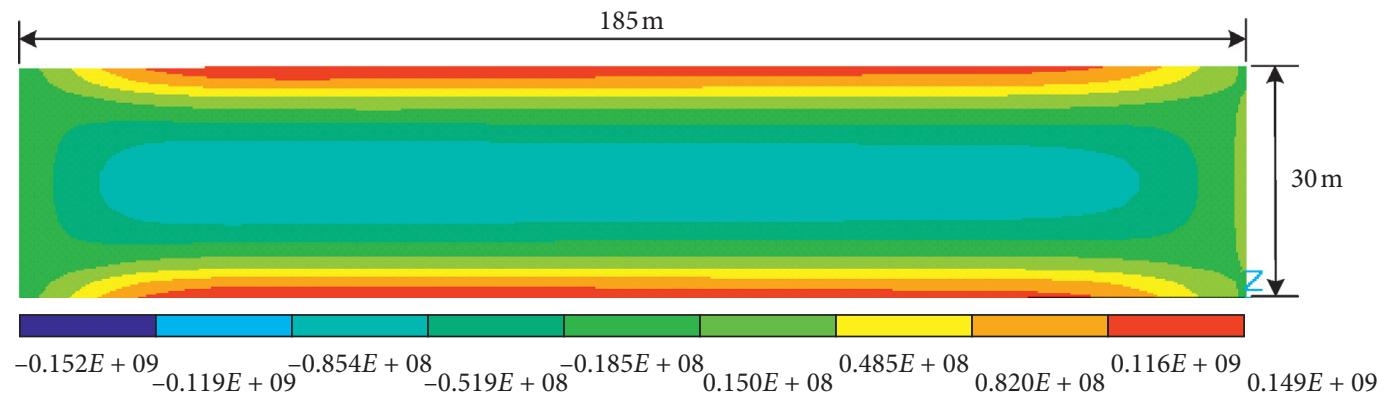

(a)

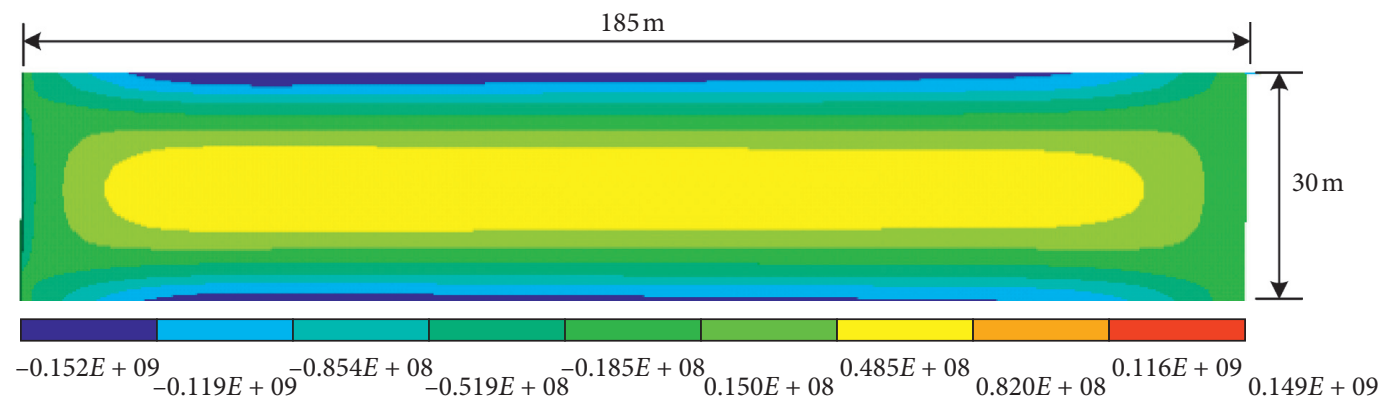

(b)

FIGURE 8: Distribution characteristics of $\sigma_{x}$ on the main roof surface during first breaking. (a) $\sigma_{x}$ on the upper surface. (b) $\sigma_{x}$ on the lower surface.

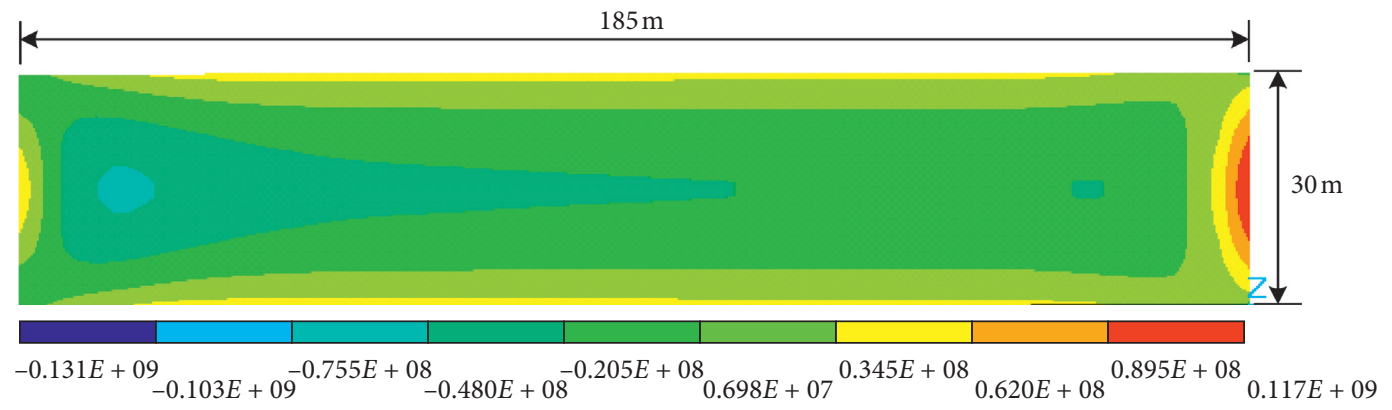

(a)

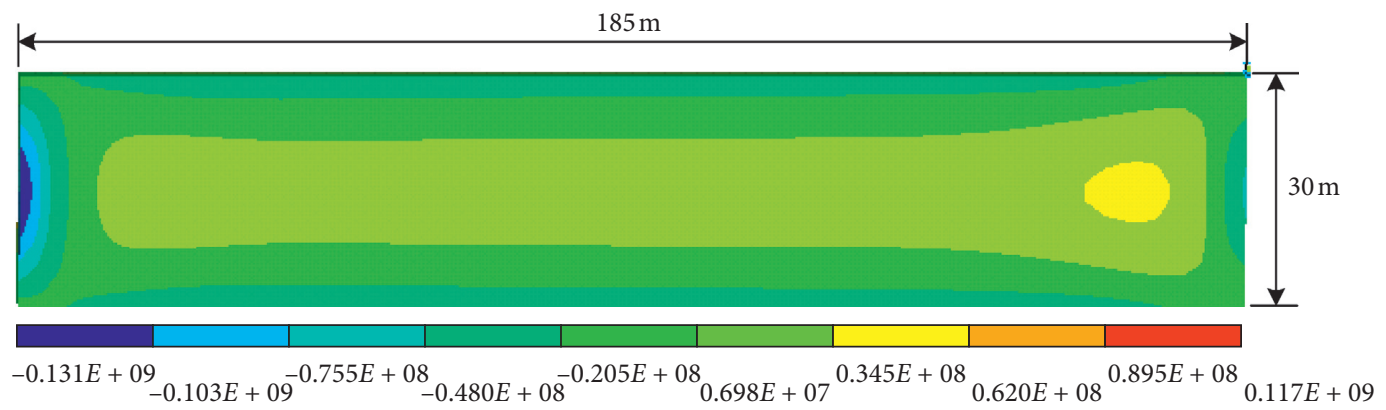

(b)

Figure 9: Distribution characteristics of $\sigma_{y}$ on the main roof surface during first breaking. (a) $\sigma_{y}$ on the upper surface. (b) $\sigma_{y}$ on the lower surface.

tensile stress of $\sigma_{x}, \sigma_{y}$ is obviously smaller than that of the upper surface. As the working face advances, $\sigma_{x}$ will exceed the tensile strength, and the rock mass will be damaged to form cracks along $x$-direction. Moreover, influenced by $\sigma_{y}$, the tensile stress concentration occurs in the area near the right side, resulting in a crack, which connects with the crack along $x$-direction, finally forming "Y" type crack. Therefore, unlike the "O-X" breaking of the horizontal seam roof [2], 


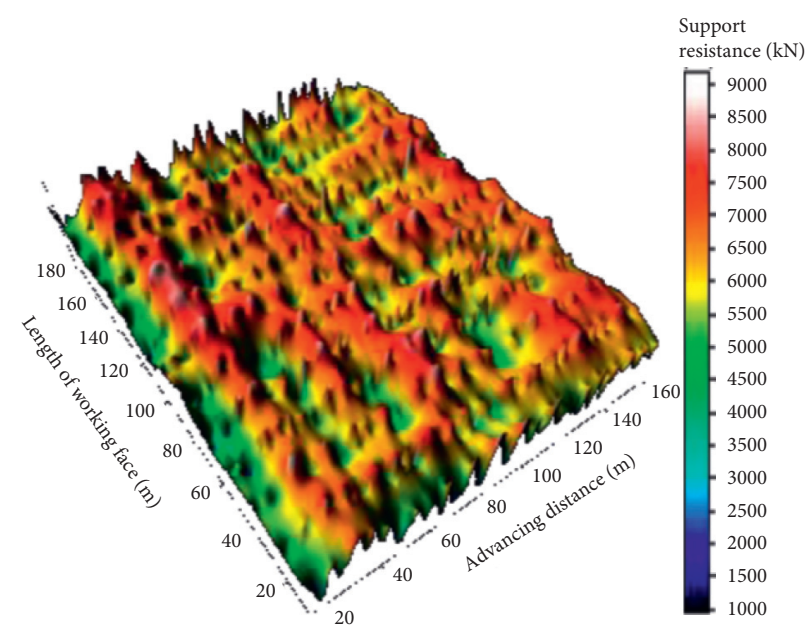

(a)

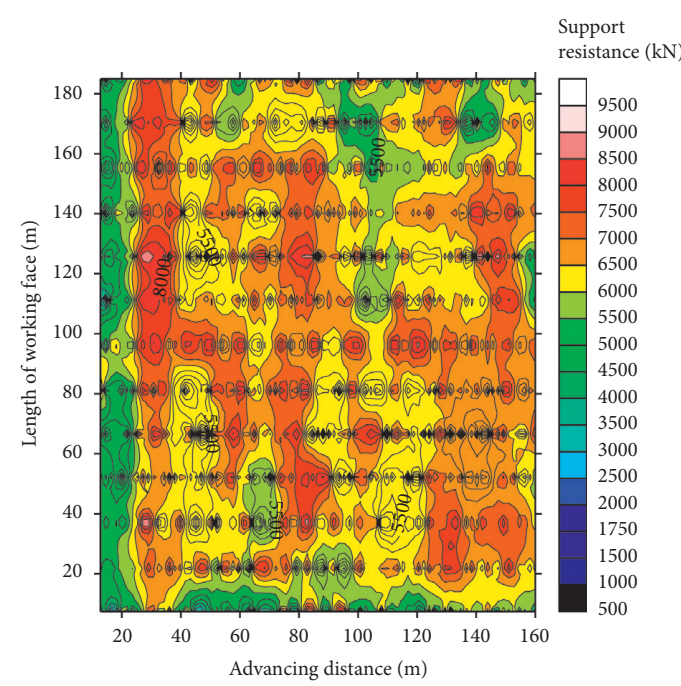

(b)

Figure 10: Contour map of working resistance of hydraulic support on working face. (a) Three-dimensional diagram. (b) Two-dimensional diagram.

TABLE 2: First weighting interval of the main roof of the working face.

\begin{tabular}{lc}
\hline Support location & First weighting interval $(\mathrm{m})$ \\
\hline Lower part & 32.2 \\
Middle lower part & 30.7 \\
Middle part & 28.5 \\
Middle upper part & 31.3 \\
Upper part & 33 \\
\hline
\end{tabular}

the high dip seam roof is characterized by a " $U-Y$ " broken morphology. The fracture sequence of high dip seam is middle part-middle upper part-middle lower part-upper part-lower part.

\section{Analysis of Project Case}

With the development of science and technology, the monitoring methods of mine pressure in stope are also diversified [13-15]. In order to fully understand the roof weighting characteristics of working face 103, pressure measuring stations were arranged on the hydraulic supports of working face before backstopping (the real-time online system of support monitoring was adopted), which can also evaluate the adaptability of hydraulic support when the working face advances. The monitoring was continued until the working face was pushed to $160 \mathrm{~m}$, and the maximum resistance of the hydraulic support in the monitoring data was generated into the contour map, as shown in Figure 10.

It can be seen from Figure 10 that the resistance variation of hydraulic support presents the shape of mountain fluctuation. When the advancing distance is about $30 \mathrm{~m}$, the working resistance of the hydraulic supports in almost all parts of the working face reaches a large value. Combined with other characteristics of rock pressure, it can be determined that the working face meets with first weighting of main roof at that time. The corresponding step distance is shown in Table 2.

From Table 2, the fracture step range of the main roof is $28.5 \mathrm{~m}-33 \mathrm{~m}$ during the first weighting, with an average of $31.1 \mathrm{~m}$. Therefore, the order of the first breaking is consistent with the general trend of numerical simulation and theoretical calculation.

\section{Conclusions}

(1) The mechanical model of the thin plate with the general form of the first breaking of the main roof in the high dip seam was established. The expressions of deflection and stress of roof were obtained. By changing the image of deflection function, the influence of different inclinations on the first breaking of roof was analyzed, and the breaking criterion of the main roof was determined.

(2) It was found that the first breaking distance of main roof decreases with the increase in dip angle of seam.

(3) The characteristics of the first breaking of the main roof in the steep seam are different from the "O-X" breaking characteristics in the horizontal or near horizontal seam. The failure mechanism of roof is determined by its tensile stress $\sigma_{y}$ along the inclination of working face.

(4) Based on behavior regularity of rock pressure in working face 103, the roof breaking order in space of the seam with high dip angle is middle-middle upper-middle lower-upper-lower. 


\section{Data Availability}

The authors believe that the data underlying the findings of this paper are publicly available, which will help ensure that the work described in our article can potentially be replicated.

\section{Conflicts of Interest}

The authors declare that they have no conflicts of interest regarding the publication of this work.

\section{References}

[1] Z. Chen, J. Feng, C. Xiao et al., "Fracture mechanical model of key roof for fully-mechanized top-coal caving in shallow thick coal seam," Journal of China Coal Society, vol. 32, no. 5, pp. 449-452, 2007.

[2] M. Qian, P. Shi, and J. Xu, Ground Pressure and Strata Control, China University of Mining and Technology Press, Xuzhou, China, 2010.

[3] G. Yin, X. Xian, G. Dai et al., "Basic behavior of strata movement in seam with deep dip angle," Chinese Journal of Geotechnical Engineering, vol. 23, no. 4, pp. 450-453, 2001.

[4] Y. Zhang, J. Cheng, X. Wang et al., "Thin plate model analysis on roof break of up-dip or down-dip mining stope," Journal of Mining and Safety Engineering, vol. 27, no. 4, pp. 487-493, 2010.

[5] J. Wang, J. Zhang, X. Gao et al., "Fracture mode and evolution of main roof stratum above longwall fully mechanized top coal caving in steeply inclined thick coal seam (I)-initial fracture," Journal of China Coal Society, vol. 40, no. 6, pp. 1353-1360, 2015.

[6] Y. Wu, P. Xie, H. Wang et al., "Incline masonry structure around the coal face of steeply dipping seam mining," Journal of China Coal Society, vol. 35, no. 8, pp. 1252-1256, 2010.

[7] H. Wang, Y. Wu, P. Xie et al., "Practice on fully mechanized coal mining in deep inclined seam with hard roof soft coal and soft floor," Journal of China Coal Society, vol. 34, no. 2, pp. 287-294, 2017.

[8] Y. Wu, D. Yun, P. Xie et al., "Progress, practice and scientific issues in steeply dipping coal seams fully-mechanized mining," Journal of China Coal Society, vol. 45, no. 1, pp. 24-34, 2020.

[9] H. Pu, Y. Huang, and R. Chen, "Mechanical analysis for X-O type fracture morphology of stope roof," Journal of China University of Mining \& Technology, vol. 40, no. 6, pp. 835-840, 2011.

[10] X. Wang, M. Gao, Y. Chen et al., "Analysis of fracturing characteristics of stope roof based on elastic thin plate theory," Metal Mine, vol. 468, no. 6, pp. 24-28, 2015.

[11] Z. Fan, D. Mao, G. Xu et al., "Analysis on the scale effect in the fully mechanized mining panel width with large mining height and dip angle," Journal of China Coal Society, vol. 41, no. 3, pp. 581-585, 2012.

[12] Z. Xu, Elasticity, Higher Education Press, Beijing, China, 4th edition, 2006.

[13] X. Meng, R. Wen, J. Liu et al., "Research on site measurement of ground behavior in fully mechanized caving mining face in high inclined seam of $1000 \mathrm{~m}$ deep mine," Coal Science and Technology, vol. 35, no. 11, pp. 14-17, 2007.

[14] K. Yang, X. Chi, and S. Liu, "Instability mechanism and control of hydraulic support in fully mechanized longwall mining with large dip," Journal of China Coal Society, vol. 43, no. 7, pp. 1821-1828, 2018.

[15] J. Chai, W. Du, D. Zhang et al., "Study on roof activity law in steeply inclined seams based on BOTDA sensing technology," Chinese Journal of Rock Mechanics and Engineering, vol. 38, no. 9, pp. 1809-1818, 2019. 